\title{
FAST: instant verification of the results of planning decisions
}

\author{
J. Janusz ${ }^{1} \&$ L. Wardeski ${ }^{2}$ \\ ${ }^{1}$ Department of Architecture, \\ University of Technology and Life Sciences, Poland \\ ${ }^{2}$ Armageddon Architectural Design Office, Poland
}

\begin{abstract}
The research focuses on generating an original IT tool, using Autodesk Autocad environment. FAST - Fast Simulation Tool - is designed to establish a viable frame for multiple development types, currently involving housing areas, mixeduse areas and selected industrial type use areas. The paper describes research in progress - the current process of the formation of this application. It defines the needs, possibilities and analogies for the tool development. Next, the basic methods of spatial planning analysis are described. The accommodation is based on the experience and the parameters collected from the spatial studies for the municipalities of Rokietnica and Oborniki. Finally, the paper has conclusions from the implementation in the spatial plan of the county of Oborniki located in the area of $340.16 \mathrm{~km}^{2}$.
\end{abstract}

Keywords: FAST, GIS, spatial planning analysis, sustainable planning.

\section{Introduction: problem description}

Each design and planning process (in architecture, town planning and spatial planning) is based on an excessive number of variables. A computer-aided design as well as GIS technologies allow for the significant improvement of, first, data collection, and then, various analytic and conclusive use of this data [1]. Planning as a process of defining the future shape of the environment requires multilayered and rich perspective acknowledging dynamic mechanisms: social, cultural, economical, ecological [2]. However, the reality of spatial planning in Poland and in general forces planners and architects to respond to short term needs and propose solutions which will quickly produce tangible, efficient results [3, 4]. 
This contradictory condition of meeting current needs and socio-political expectations while simultaneously providing reasonable and continuous effects may become possible only when many diverse aspects of planning problems are processed successfully within limited amount of time, usually marked by the election-related cycles (regardless of political effects of such actions). The concept of FAST - Fast Simulation Tool - is based on these assumptions. The simple IT tool is aimed at supporting sustainable planning on local and regional level. In its current stage it is a work in progress with practical implementations listed below.

\section{Spatial planning: information model}

The evolution of spatial planning as a discipline displays a shift from the focus on development, economy and infrastructure, which marked the expansion of contemporary cities in the 50 s to 70 s [5] to the concept of sustainable organism, relying on social ties and local ecologies, with the understanding of the ecology in a broader sense. At the turn of millennia the sustainable development in its amorphous, ambiguous definition, has been established as the template of the ideal city. While the definition itself is not clear, mechanisms and the application of sustainability has proven its efficient and positive influence on the condition of urban life, but only partially and at a price. Recent years proved wealth, globalization and personal freedom, marking the liberal approach to planning on the one hand, and public interest, accommodation of individual needs of end users and balance between nature and civilization supported by clear value-based criteria often clash and compete in a gameplay of urban space [6]. Speculation with land, focus on temporary solutions facilitating short-term perspective investments does not correspond with good quality of planning services which local authorities should aim at delivering for local communities. However, the developers have experts of particular focus at their disposal, thus receiving initial upper hand in above mentioned power game. The development of spatial planning in the context of sustainability is a broad issue. It includes both changes in the social and technological field [7] as well as verification of approach and design purposes $[8,9]$. Much attention is paid to the problem of ecology $[10,11]$. Moreover, this phenomenon plays out at many levels of the complex structure of the spatial planning policy [12-14]. This model forces continuous development of the analytical framework simultaneously with increasing the amount of available information. This fact was discussed more than a quarter of a century ago [15]. As a result, in last decades it has caused the design reorientation towards holistic, context-aware information model [15]. Universities ought to put much emphasis on development of new tools and software to give designers a feedback of both existing information database, and the impact of particular decisions. The practical implementation of new technologies and databases linked with GIS helps solving among others the issues of utility supplies, crucial from the government spatial planning policy point of view [16]. These great opportunities have been recognized by the administration officials, so much effort is put on the implementation of advanced IT tools in projects connected with spatial planning policy [17]. It raises the fundamental questions: what way such implementation 
should look like and on what tools should it be based on? It requires a clear definition of the needs and priorities for specific tasks to make a choice from wide spectrum of possibilities [18]. This allows to select and adjust a specific software, or more broadly, the work environment to find the optimum solution. Moreover, the specificity of GIS systems is their openness and flexibility, which leads to the necessity of creation the individual solutions and mechanisms [19,20]. Essentially the functions of the software can be divided into two groups. The first group provides with information and analysis from GIS databases and the second group analyzes the impact of design solutions. The group creates potential to profound customization and individualization of computing algorithms, therefore this function has been selected as the base for FAST. The problems of wider scale, of overall quality of spatial planning, hardly can be solved by the single IT tool, and FAST authors do not aspire to do it. Instead it is a modest application concentrated on quick processing and delivery of crucial data, preparing the decision process. The methodological aspect of FAST implementation relies on immediate engrafting value-based decision process from preliminary stages of planning. The tool brings the problem of values to the core of discourse on spatial planning and consequences of decisions related to planning, which is different both from reactive planning motivated mainly by investor/developer actions, and from ready-and-fixed long-term perspective planning unable to absorb dynamic and necessary changes of possible everyday shifts [21].

\section{Guidelines}

The concept of an application has arisen as a tool for cooperation with local authorities on various spatial plans, including the county of Oborniki. Its main goal was to create a framework for the estimation of certain parameters, such as average demographic levels, the demand for utilities and the rates of investment. The project team was already supplied with a comprehensive database information about local area, but still requires a tool for simulation of certain project decisions. The search for an appropriate solution was based on the certain assumptions. First of all, it had to be a flexible tool, which allows for full accommodation to local specificity and calibration of estimations. It should also provide with the possibility to implement in the early design stages. Moreover, in principle the application had to work as a supplement to the established work environment and completely fit in with its logic and software. Therefore there was no aspiration to replace software, but rather support them. The nature of the task assumed immediate effect, which allows for quick verification of solutions. Finally, intuitiveness and simplicity were important. It is safe to say that they were key issues, because FAST was meant to be used not only by the design team, but also by government officials and other participants. Much emphasis was put to the problem of guide potential user through decision and set-up process. The main problem was to make the tool both intuitive and elastic. The software model which has simple features for beginners and simultaneously allows for advanced randomization and development during work [22]. The issues of spatial planning are set at many layers and levels ranging from the most local to the nation-wide. 
The process of investments' planning in a more distant perspective requires consideration of complicated interactions and solutions of spatial conflicts. The location of strategic investments such as large scale industry, infrastructure and energy management involves multifaceted analyses of their efficiency as well as the negative impacts and limitations. This contrast creates so many possibilities and involves so many variables that there are no ready-made solutions and procedures. The practical time limitation requires consideration of a multitude of development scenarios based on limited amount of preliminary data. It is necessary to make decisions that are often irreversible [23]. Authorities take on this great responsibility both in public investments and supervision of land use. It leads to the conclusion that the proper IT tool should define holistic influence on the environment, dangers and risks for inhabitants of urbanized zones and longrange prospects, besides delivery of basic approximation of planed land use parameters and requirement.

\section{The tool description}

The principle of functionality of FAST was to provide specific figures on certain planned investments, which allows for verifying technical possibility and the potential impact. It is still a work in progress and along with the development of the county project, further analytic mechanisms are being developed. The housing area module was selected as the first and most necessary one. It estimates the number of properties, apartments, area occupied by buildings, demographic data, demand for water, energy, gas, sewerage utility, and more others. As a CAD environment Autodesk Autocad was selected. Along with ArcGIS it was used by the participants of the design process. Besides functions described previously, the software allows for effective collaboration with external databases linked with GIS and external mechanisms for computing [1]. The FAST is written in VBA which allows for compatibility with Autocad R14 released in 1997 and as a language it is still being developed. In Autocad 2014, the version of VBA 7.0 64x was applied. It works also with ZWCAD and DraftSight, however the code can be and will be translated to .NET.

The workflow is based on the basic interface used to show the results of calculations (fig. 2). It includes a summary of the results in tables. Each marked area is represented in a table. The combined data such as the sum and the average is also shown. After changing the geometric model, the results can be updated. The sheet can be exported to Excel. The interface allows us to skip to creation window, which allows to assign categories to objects (fig. 1). It has two modes: simplified for those familiar with the interface and expanded or beginners. The first allows for quick select multiple objects, while the second guides through the series of questions helping to define a category. The logic of the estimation is based on the objects connected with different categories, defined according to the local environment. 


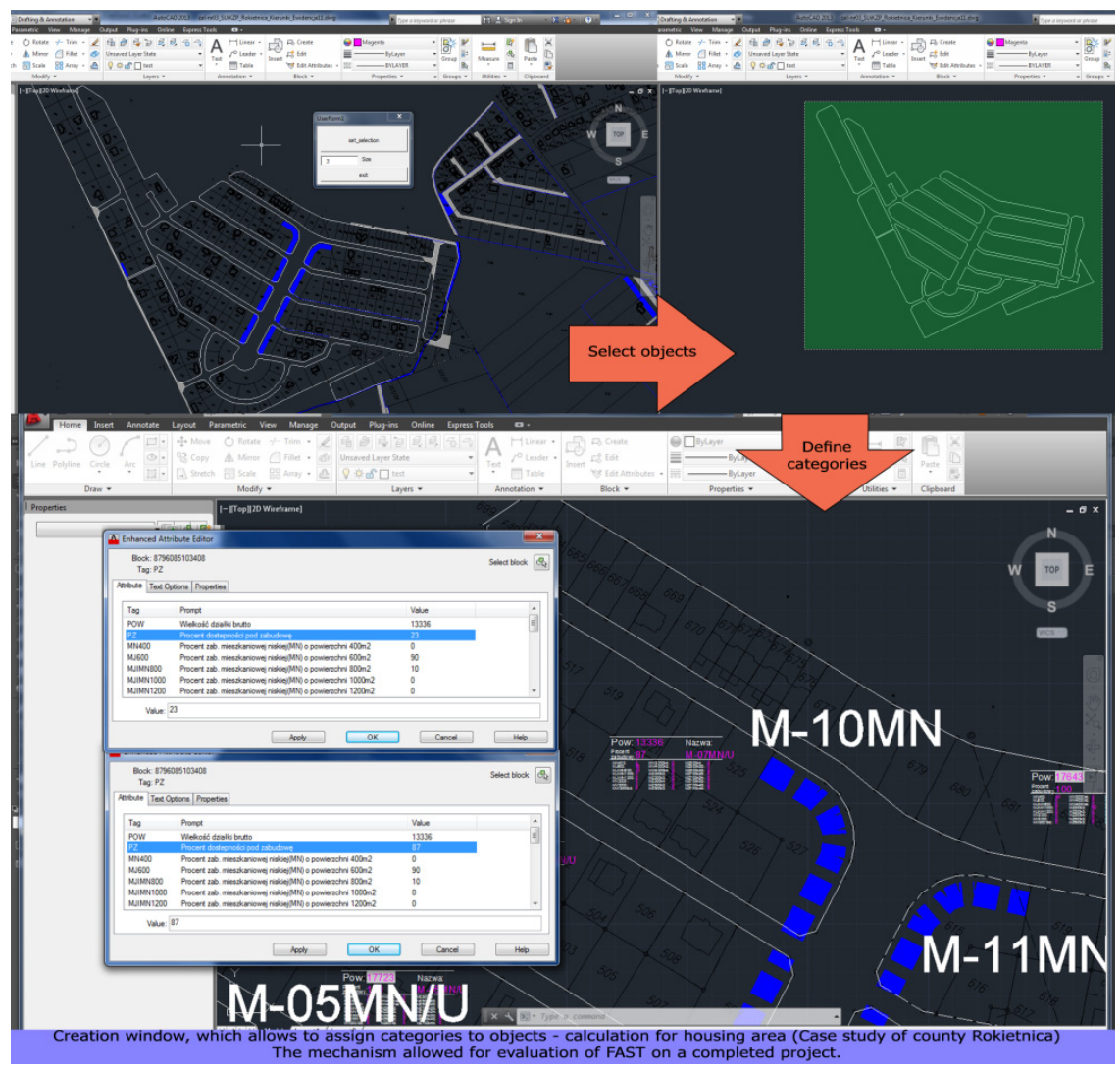

Figure 1: The creation window, which allows the assignment of categories to objects.

\section{Estimation algorithm}

The main requirement from the investor was information about utilities in the context of area development. The principles of creating a mechanism are the same for all variables. The script performs a calculation on the spatial and numeric parameters. In this aspect, the accuracy is based on several levels of information, ranging from the most general and global to the most local and subjective.

\subsection{Global categories}

The most general and fundamental source of information was the study of the literature in search of established categories and indicators. The study had to be carried out in a similar environment. This was served as a guideline for the methodology of data analysis, especially in terms of optimal solution [24] and estimated time impact and perspectives [25]. More detailed studies were 


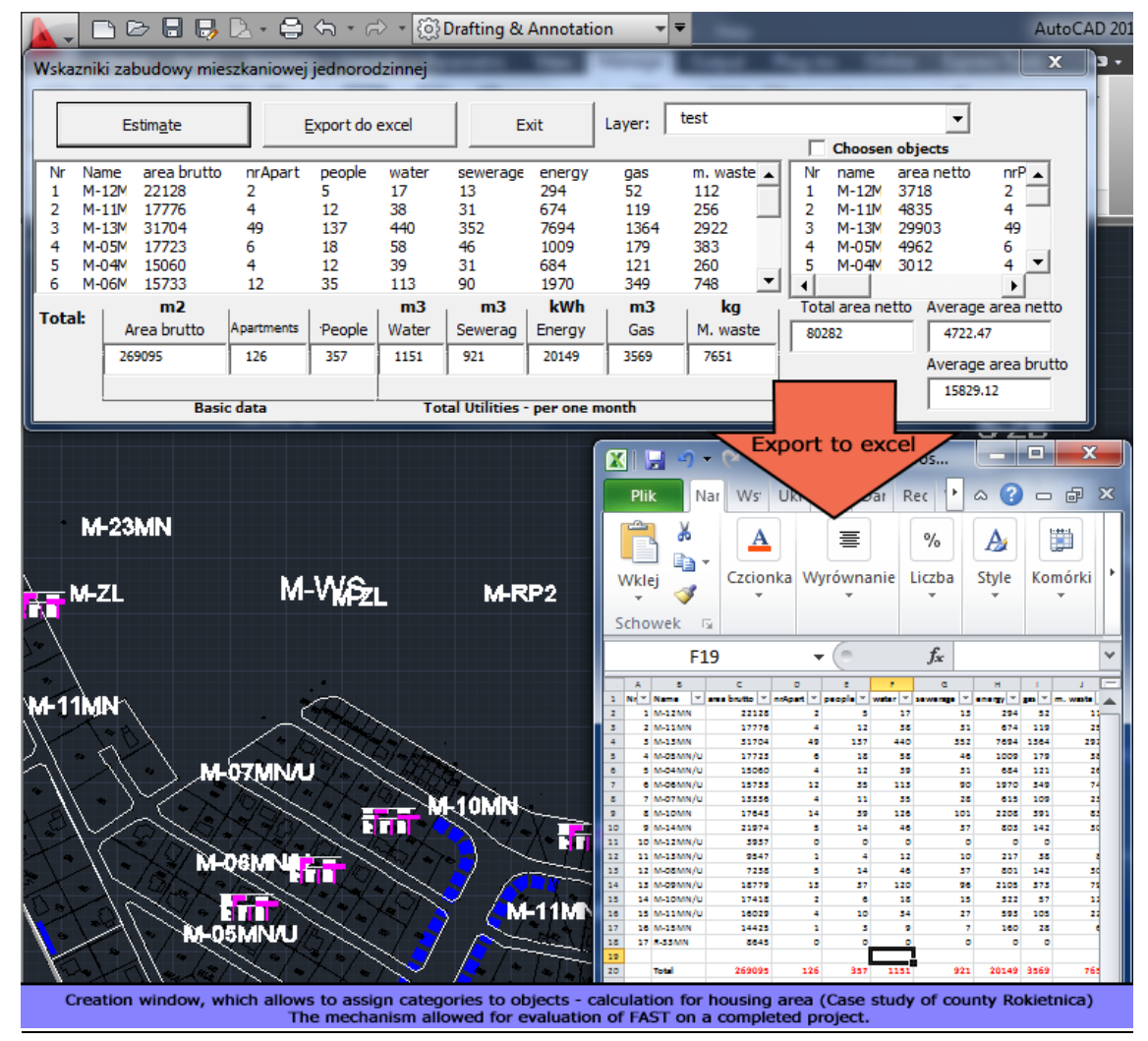

Figure 2: The estimation interface.

considered as the directives to define coefficients and estimate the potential aberration. As an example an analysis of water use at a given population density and type of building [26] or thermal performance depending on the building type [27] might be presented. Studies are also required to define spatial relations such as the influence zones of impact [23].

\subsection{The statistics and GIS}

It is the basic data to estimate the individual parameters. Global data from the whole country is used to build general categories [28]. This allows to build universal estimation modules with the lesser degree of accuracy, which may be sufficient in predesign process. Regional statistics [29-31] and GIS databases [32] allow for calibration to more accurate tasks. Such a methodology obliges to clarify in the result table what degree of accuracy ensures the tool. A certain type of land use can be summed up to the basic variable. In FAST calculation for housing area bases on users. The overall statistics allows to estimate, first their type and number in certain type of land use, and next other required parameters. The use of nationwide indicators is inaccurate, so the next step is to make corrections on the 
information specific to a particular location basic on local statistics and GIS. In order to obtain reliable information, even on the overall data, it is necessary to pay special attention to the correct methodical frame, taking into account technological changes and the specifics of certain objects.

\subsection{Case study}

Another mechanism is appropriate to evaluate categories based on the similar areas. In this case study, we used the project of Rokietnica county, designed by the time before 2010. The areas of projects Rokietnica and Oborniki are in the same region which validate the choice. This project has provided us with a rich database for calibration, firstly, because it was subjected to a thorough analysis, and secondly, because it had four years to be verified. It allowed for evaluation of FAST on a completed project. For good effectiveness it should be performed on both small and large areas. Actual parameters may be different from the statistical calculations. When derogation occurs, it is important to find the source and to take into account the relevant amendments. Some of them are global associated with technological development, which among others, changes the building thermal and energy performance. Some, however, arise from the specific region. Statistical methods have already indicated that the economic situation significantly affects the number of people living in one apartment. It was also confirmed by the conducted case study. The problems reported by local authorities gave the best feedback. In county Rokietnica some problems with water supplies occurred. Indeed, water consumption was greater than statistical in the spring and summer. It was connected with highly developed individual gardening in this region. The number of variables indicates that the tool has to be very flexible which allows for continuous development of modules library.

\subsection{Implementation and auto-calibration}

Finally, the calibration takes place while working on the current project. Surrounding areas provide partial guidelines for specifics land use, which may be included in the relevant modules. Such actions allow to create a database of flexible modules on which the designer can quickly create simulations of certain design decisions. Modules may be a form of communication between project participants and the field of discourse and further studies development. It allows to present both ingredients and expected results of spatial reaction. The advantage of open platforms such as FAST is the possibility for better establishment of the basic assumptions and guidelines. The information obtained from the authorities also indicate which parameters are crucial and therefore should be thoroughly determined and which are less important in estimations. In this context, what we obtain is the platform for analysis and discourse between experts, planners, authorities investors and developers. This approach builds a model of discussion based on the defined numbers and expectations. 


\section{Perspectives}

Both the project of Oborniki county and FAST are still in progress, although the effects are already visible. Currently the calculation modules for wind turbines are finalized and the modules for the utility supplies in housing area are implemented. The further objectives are aimed at the other renewable energy sources. These issues also require multi-level analysis and the holistic context-aware approach [33]. This also leads to another step: the issue of spatial conflicts and the relationships between individual elements. Object oriented model allows for the creation of the complicated database. Proper calculations performed on the collected data can estimate among others the impact of infrastructural and industry objects, traffic management and requirement for special services (e.g. sport and education). At the same time, the function used for the estimation of the utility supplies, is being developed with new computational modules defining other land uses such as services and industry. A complete description of the case study will be possible after completing the project of Oborniki county.

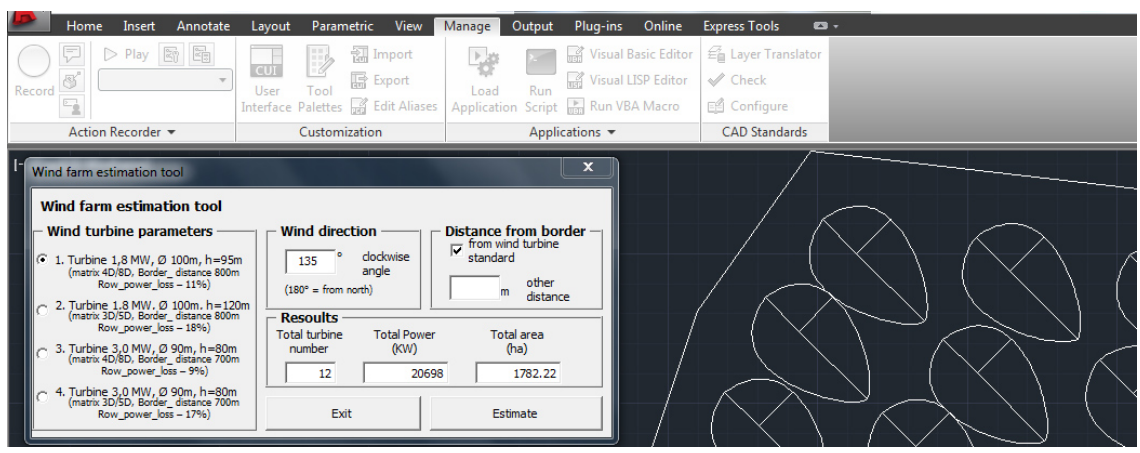

Figure 3: Wind turbines simulation.

\section{References}

[1] El-Az, T., From CAD to GIS: Editing and Distributing Geographic Information from CAD Software. Proc. FIG Working Week 2009, Surveyors Key Role in Accelerated Development, eds. C. Potsiou: Eilat, Israel, pp. 3/9-6/9, 2009.

[2] Anusz, S., Gis And The National Spatial Organisation Policy. Annals of geomatics. 6(3), pp. 60-65, 2008.

[3] Hajduk, S. \& Baran, A., Municipal planning and investment process: problematic issues. Czasopismo poświęcone potrzebom nauki i praktyki, Wydawnictwo Uniwersytetu w Białymstoku, 2(62), pp. 119-121, 2013.

[4] Jones C. Baker M. Carter J. Jay S. Short M. Wood C., Strategic Environmental assessment and land use planning: An international Evaluation, Earthscan: London, United Kingdom, pp. 154-155, 2005. 
[5] Hall, P., The Centenary of Modern Planning (Chapter 2). Urban Planning in a Changing World, ed. R. Freeston, E\&FN SPON, London, pp. 20-39, 2000.

[6] Gleeson, B. \& Low, N., Is Planning History? (chapter 15). Urban Planning in a Changing World, ed. R. Freestone E\&FN SPON, London, pp. 269-283, 2000.

[7] Hanzl, M., Information technology as a tool of public participation in the spatial planning. Annals of geomatics, 6(3), pp. 87-91, 2008.

[8] Faludi, A., The Performance of Spatial Planning. Planning Practice and Research, 15(4), pp. 201-303, 2000.

[9] Waddell, P., Integrated Land Use and Transportation Planning and Modelling: Addressing Challenges in Research and Practice. Transport Reviews, 31(2), p. 215, 2011.

[10] Young, J. Watt, A. Nowicki, P. Alard, D. Clitherow, J. Henle, K. Johnson, R. Laczko, E. Cracken, D. Matouch, S. Niemela J. \& Richards, C., Towards sustainable land use: identifying and managing the conflicts between human activities and biodiversity conservation in Europe. Biodiversity and Conservation, 14(7), pp. 1643-1644, 2005.

[11] Silberstein J. \& Maser C., Land Use Planning for Sustainable Development, 2nd Edition. CRC Press: Taylor \& Francis, Boca Raton, Florida, pp. 37-45, 2013.

[12] Hajer, M. \& Zonneveld, W.,Spatial Planning in the Network SocietyRethinking the Principles of Planning in the Netherlands. European Planning Studies, 8(3), pp. 339, 341, 2000.

[13] Foppen, P. Opdam, R. \& Vos, C., Bridging the gap between ecology and spatial planning in landscape ecology. Landscape Ecology, 16(8), pp. 768770, 2002.

[14] Skiba M., The role of law and economic mechanisms in the formation of the image of a town. Scientific journals $n r 150$ University of Zielonogora, 150(30), pp. 145-147, 2013.

[15] Bruton, M. \& Nicholson, D., Local Planning in Practices, Hutchinson, London, pp. 61-62, 1987.

[16] Malszewski, J., GIS-based land-use suitability analysis: a critical Overview. Progress in Planning, 62(1), pp. 9-14, 2004.

[17] Feyissa, T., GIS Based Assessment In Urban Facilities And Utilities Planning: A Case Of Nekemte Town, Oromia Region, Ethiopia. proc. global Geospatial Conference 2013, eds. E. Dagnew, pp. 6-10, 2013.

[18] Białousz, S., Education in spatial information systems for public administration needs, state of art, perspectives. Annals of geomatics, 5(9), pp. 87-91, 2007.

[19] Eldrandaly K., GIS software selection: a multi criteria decision making approach. Applied GIS an international, refereed, open source journal, 3(5), pp. 8-10, 2007.

[20] Wolf, E. B. Creating contiguous cartograms in ArcGIS 9. Proc. of 2005 ESRI International User Conference 25, Glenn Letham, pp. 5-9, 2005. 
[21] Wunderlich, A. L., Improving ArcGIS workflow: Automation using Visual Basic for Applications (VBA). Digital Mapping Techniques '09Workshop Proceedings, eds. D.R. Soller. pp. 21-23, 2010.

[22] Falessi D. Cantone G. Kazman R. Kazman R. \& Kruchten P., DecisionMaking Techniques for Software Architecture Design: A Comparative Survey.' Journal ACM Computing Surveys, 43(4), pp. 33:7-33:9, 2011.

[23] Barelkowski, R., Planning for sustainable development of energy infrastructure: FAST - Fast Simulation Tool, International Journal of Energy Management and Production, in print, pp. 12, 2014.

[24] Dabrowska-Milewska, G. Urban Planning Standards for Residential Areas - Chosen Issues. ARCHITECTURAE et ARTIBUS - 3(2), pp. 23-27, 2010.

[25] Czado, J. Chances of rehabilitation for large public housing projects based on an example of western countries. Technical Transaction-Architecture, 29(7), pp. 29-31, 2012.

[26] Podwojci, P. Serejko G. Wojciechowski, M. Biedugnis, S, Chojnacka, P. Smolarkiewicz, M. Czapczuk A. Unit Water Consumption and Apparent Losses in the Multi-family Housing on the Example of Mazovian Housing Association in Płock. Annual Set The Environment Protection 11(2), pp. 1147-1151, 2009.

[27] Turecki A. Calculation method of town energy consumption carried out by building energy audid software. Technical Transaction - Architecture, 14(6), pp. 203-204, 2010.

[28] GUS - Central Statistical Office of Poland, http://stat.gov.pl

[29] Statistical Office in Poznan, http://poznan.stat.gov.pl/

[30] County of Rokietnica, County in numbers, http://www.rokietnica.pl /pl/gmina_w_liczbach.php

[31] County of Oborniki, Information about the county, http://www.oborniki.pl /miejscowosci-gminy-oborniki/

[32] Geostatistics portal http://geo.stat.gov.pl/imap/

[33] Barelkowski, R., The methodology of evaluation and determination of "RES" project allocation' space \& FORM - scientific journal, 16, pp. 385$389,2011$. 